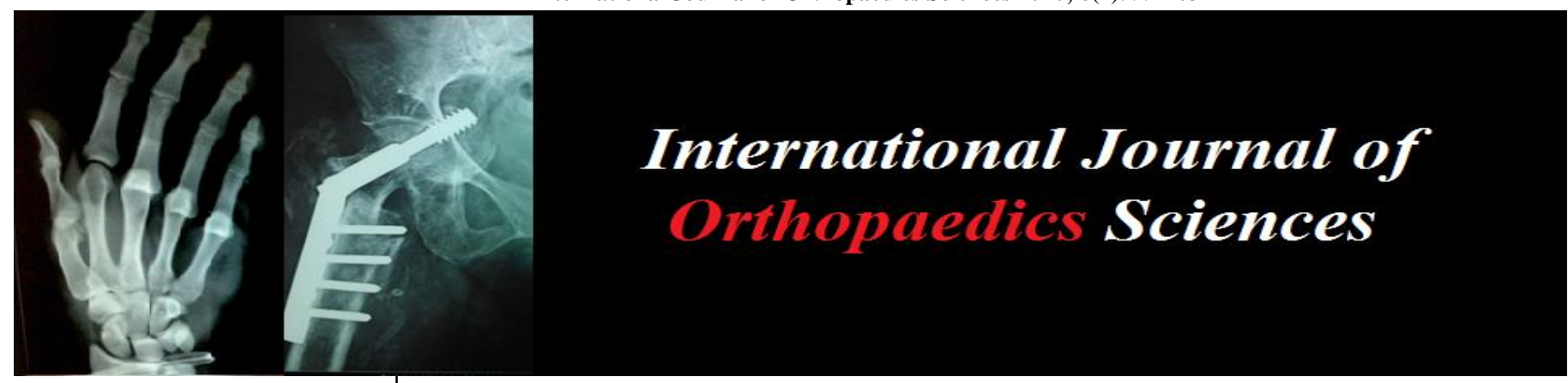

E-ISSN: 2395-1958

P-ISSN: 2706-6630

IJOS 2020; 6(2): 99-103

(C) 2020 IJOS

www.orthopaper.com

Received: 14-01-2020

Accepted: 17-02-2020

\section{Ayouba Gamal}

Department of orthopaedic and

traumatology. Teaching Hospital

of Sylvanus Olympio, Lome-

Togo, Togo

\section{Akloa Kolima Ehlissou Komlavi} Department of orthopaedic and traumatology. Teaching Hospital of Sylvanus Olympio. BP 57. Lome-Togo.

Towoezim Tchaa Hodabalo Department of orthopaedic and traumatology. Teaching Hospital of Kara, Kara-Togo

Dellanh Yaovi Yannick Department of orthopaedic and traumatology. Teaching Hospital of Sokode, Togo

\section{Bakriga Batarabadja}

Departement of orthopaedic and traumatology. Sylvanus Olympio teaching hospital, Togo

Kombate Noufanague Kanfitine Department of orthopaedic and traumatology. Teaching Hospital Saint-Jean de Dieu d'Afagnan. Togo

\section{Abalo Anani}

Department of orthopaedic and traumatology. Teaching Hospital of Sylvanus Olympio. BP 57. Lome-Togo

\section{Interest of circular external fixator in orthopaedic in low-income country}

\author{
Ayouba Gamal, Akloa Kolima Ehlissou Komlavi, Towoezim Tchaa \\ Hodabalo, Dellanh Yaovi Yannick, Bakriga Batarabadja, Kombate \\ Noufanague Kanfitine and Abalo Anani
}

DOI: $\underline{\text { https://doi.org/10.22271/ortho.2020.v6.i2b.2024 }}$

\section{Abstract}

Objective: The purpose of this study was to describe the indications of Ilizarov's technique in orthopedic trauma and their results.

Material and method: The study involved a retrospective multicenter cohort. It included patients treated with Ilizarov's technique between July 2014 and September 2019 and followed through to recovery.

The analysis focused on types of lesions, intraoperative data, complications, cure and failure rates. Only the pins were the responsibility of the patient and cost between 60,000 to 120,000 CFA (91, 5-183 euros).

Results: Forty-seven patients were treated. The average age was 37.4 years. Males represented $63.8 \%$. The main diagnoses were: tibial fractures $(n=31 ; 65.9 \%)$, including 14 fractures of the tibial plateau; vicious ankle calluses $(3 ; 6.4 \%)$; loss of bone substances $(3 ; 6.4 \%)$.

The main interventions carried out were: Osteosynthesis $(\mathrm{n}=34 ; 72.3 \%)$; ankle arthrodesis $(\mathrm{n}=5$; $10.6 \%)$; equine varus foot correction $(\mathrm{n}=4 ; 8.5 \%)$. The average duration of an intervention was 130.5 min. the average ablation time was 98.7 days. The cure rate was $95.6 \%$. The main complications were: infection on a spindle $(n=11 ; 23.4 \%)$; pain $(n=6 ; 12.8 \%)$, stiff knee $(n=7 ; 15.9 \%)$.

Conclusion: The rate of positive results is similar to that observed in the literature. Ilizarov's external fixator has achieved satisfactory results for complex leg and ankle injuries at a reduced cost.

Keywords: Ilizarov technique, Africa, outcome

\section{Introduction}

The practice of orthopedic trauma in low incomes countries is constantly faced with insufficient technical support. In the wide range of fixation bone, external fixators occupy a prominent place. Ilizarov's circular external fixator (ICEF) was developed by Gavril Abramovich Ilizarov in Russia during the Cold War. It was popularized in Europe from 1981 after an Italian photojournalist, Carlo Mauri, was treated for a tibial non-union by Dr. Ilizarov [1]. This circular fixation has several advantages for the treatment of complex and complicated fractures, the correction of deformities of the limbs, the treatment of osteomyelitis due to the minimally invasive nature of the application and the establishment of optimal biomechanics ${ }^{[1]}$, ${ }^{[2]}$ to healing.

In Africa, the authors report good outcomes after tibial plateau and diaphyseal fractures treated with ICEF [3], [4], [5]. In Togo, ICEF has been available since 2014. It was provided by the Podiatry Overseas Association. This association during several humanitarian missions' trip from 2014 to 2016 which allowed to take care of several patients and also trained a surgeon to the technique for application of the ICEF. The objective of this study was to describe the various indications of ICEF, the results of this treatment and describe the interests of this material in a country with limited resources.

\section{Patients and methods}

Patients

The multicenter retrospective study was carried out from July 2014 to September 2019. It included all patients whose pathology required the use of the circular external fixator Ilizarov

\footnotetext{
Corresponding Author:

Department of orthopaedic and traumatology. Teaching Hospital of Sylvanus Olympio, LomeTogo, Togo
} 
(ICEF) and who were regular follow up during 6 months after frame removal. We identified two groups of patients according to type of diagnosis (table 1): the trauma group (TG) included all fractures and trauma of leg and foot; and non-trauma group (NTG) included the complications and sequalae of fractures, leg and foot deformities. The fractures of the tibial plateau were described according to Schatzker classification [6]. Tibia shaft fractures were described according to the AO classification ${ }^{[7]}$. Open fractures were described according to Gustilo Anderson ${ }^{[8]}$ and soft tissues injuries in closed fractures were classified according to Tscherne and Gotzen classification ${ }^{[9]}$. The following clinicals parameters were assessed: type of diagnoses, types of surgery, healing time, tolerance of the frame, complications. Complications have been described in two groups ${ }^{[10]}$ : minor complications that do not require secondary procedure and major complications that require another surgery to correct them.

\section{The procedure}

The Ilizarov set was available and free of fees. A dozen smooth K-wire from and 2 to 4 olives K-wire were required for frame. The total cost of the pins was estimated between 60,000 to 91.5 to 183 euros $(60,000$ to $120,000 \mathrm{CFA})$. According the radiological patterns, one or more screws can be associated to fixation.

After locoregional anesthesia, the supine position was used for all patients with. The fluoroscopy, traction table and tourniquet were used as directed. Two to four surgeons and residents were required for a procedure. The building of Ilizarov's apparatus was done intraoperatively.

\section{Results}

A total of 47 patients were treated with ICEF during the study period. The average age was $37.4+/-14$ [11 - 63] years old. There were 30 men $(63.8 \%)$ and 17 women $(36.2 \%)$. All the lesions treated concerned the leg and or the foot. There were $32(68.1 \%)$ patients in the TG group and $15(31.9 \%)$ in the NTG group.

In the trauma group there were all tibia fractures $(n=31$; $65.9 \%$ ), an open dislocation $(2.1 \%)$ of the ankle type IIIB of Gustilo / Anderson. The tibia fractures were open fractures $(10 ; 31.3 \%)$ and closed fractures $(21 ; 65.6 \%)$. Open fractures included types IIIA $(2 ; 6.3 \%)$, types IIIB $(7 ; 21.9 \%)$ and type IIIC $(1 ; 3.1 \%)$. The tibia fractures site was: tibial plateau (14;
$45.2 \%)$ type IV to VI of Schatzker; tibia shaft $(13 ; 41.9 \%)$ type 43-B2 to 43-C3; tibia pilon $(3 ; 9.7 \%)$ and a stepped shaft and tibial plateau fracture $(3.2 \%)$. In the NTG group there were: tibia distal malunion $(3 ; 6.4 \%)$; the neglected clubfoot $(4 ; 8.5 \%)$, tibia shaft bone defect $(3 ; 6.4 \%)$, talus necrosis and tibia shaft non-union. All of the diagnoses are reported in Table 1.

The fluoroscopy was required in $26(55.3 \%)$ surgical procedures and was not required in $21(44.7 \%)$ procedures. The procedure included : all tibia fractures osteosynthesis (fig. 1) $(65.9 \%)$, bone fixation after bone defect reconstruction and osteotomy(fig.2A) (6.4\%); ankle fusion (fig. 2B) (10.6\%), correction of neglected clubfoot $(8.5 \%)$, the others procedures were ankle stabilization after reduction of open dislocation, temporary stabilization of the femur after bone resection for osteomyelitis and two circular skin graft protection on leg (fig. 2C). The frame was applied for definitive management in $46(97.9 \%)$ patients and in one patient $(2.1 \%)$ for temporary fixation after bone resection in femur for osteomyelitis. The frame was: tibio-tibial $(32 ; 68.1 \%)$, tibio-foot $(14 ; 29.8 \%)$ and once femoro-femoral $(2.1 \%)$. The mean duration of procedure was $130.5+/-37$ [26-196] min. The shortest procedure (26min) was a fixative to protect a circular skin graft on the leg. The longest procedure (196 min) was a fixation of tibial plateau fracture. The mean duration was $162.6 \mathrm{~min}$ in ankle fusion, and $152.2 \mathrm{~min}$ in tibial plateau fracture fixation. The different types of procedures were reported in Table 2.

Table 1: Distribution of different diagnoses

\begin{tabular}{|c|c|c|c|}
\hline & & $\mathbf{N}$ & $\%$ \\
\hline \multirow{4}{*}{ Tibia fractures } & Plateau type & 14 & 31,9 \\
\hline & Shaft & 13 & 25,5 \\
\hline & Pilon & 3 & 6,4 \\
\hline & Compound plateau and shaft & 1 & 2,1 \\
\hline \multicolumn{2}{|r|}{ Neglected clubfoot } & 4 & 10,6 \\
\hline \multicolumn{2}{|c|}{ Bimallealor mal-union } & 2 & 4,2 \\
\hline \multicolumn{2}{|c|}{ Tibia shaft bone defect } & 2 & 4,2 \\
\hline \multicolumn{2}{|c|}{ Skin defect } & 2 & 4,2 \\
\hline \multicolumn{2}{|c|}{ Open type IIIC ankle dislocation } & 1 & 2,1 \\
\hline \multicolumn{2}{|c|}{ Charcot foot } & 1 & 2,1 \\
\hline \multicolumn{2}{|c|}{ Failure after ankle fusion with talus necrosis } & 1 & 2,1 \\
\hline \multicolumn{2}{|c|}{ Femur shaft bone defect } & 1 & 2,1 \\
\hline \multicolumn{2}{|c|}{ Tibia non-union } & 1 & 2,1 \\
\hline \multicolumn{2}{|c|}{ Tibia distal mal-union } & 1 & 2,1 \\
\hline \multicolumn{2}{|r|}{ Total } & 47 & 100 \\
\hline
\end{tabular}
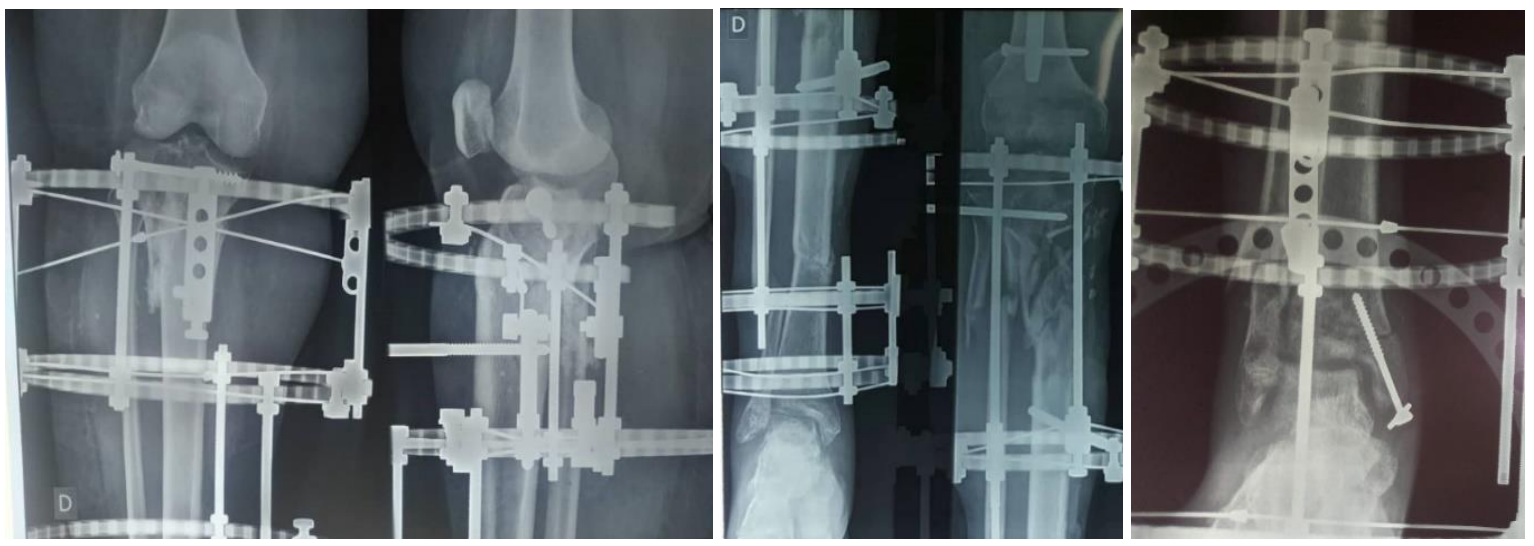

Fig 1: Radiological aspect after bone fixation for all tibia fractures.

A: tibia plateau fracture fixation. B: tibia plateau and shaft fracture. C: pilon tibial fracture. 

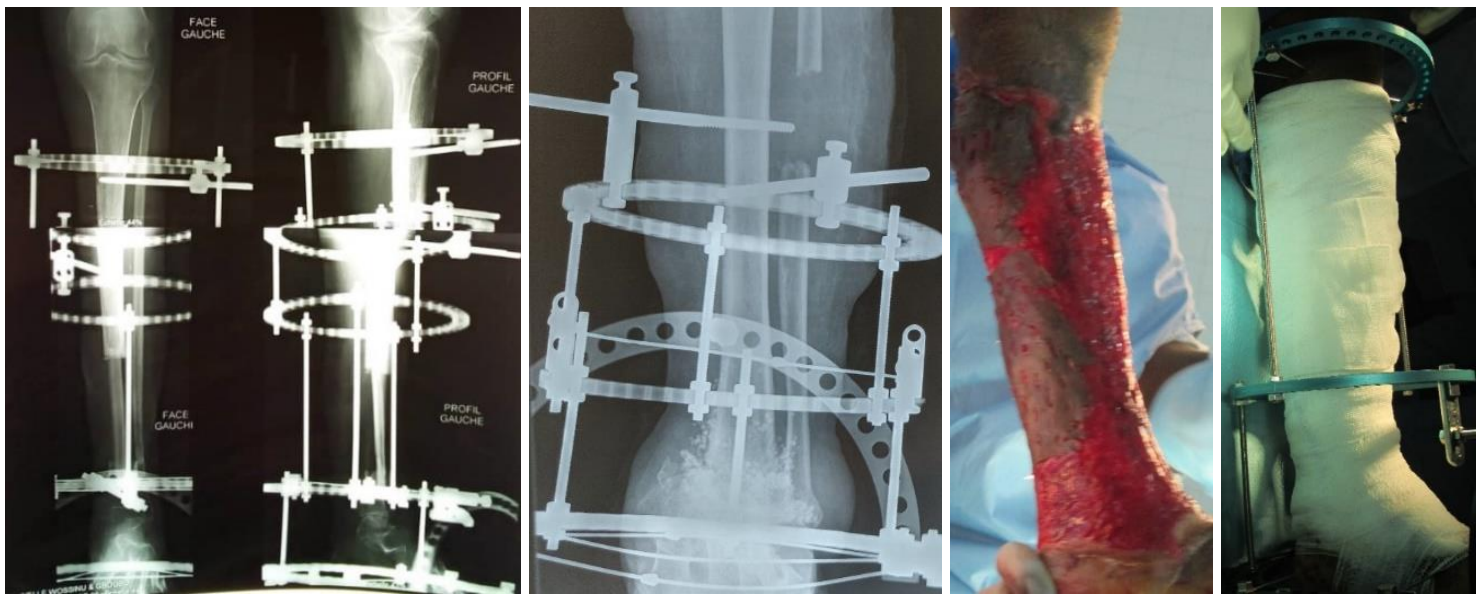

Fig 2: Different types of fixation by ICEF in non trauma group

A: osteosynthesis after free fibula flap for tibia reconstruction. B: ankle fusion. C, D: circular skin graft protected by Ilizarov frame

Complications were minor in 31 patients $(65.9 \%)$ and major in $5(10.6 \%)$ patients. One lesion injury was observed in a patient where a proximal epiphyseal pin of the tibia was in conflict with the common fibular nerve. The K-wire position was changed the next day during another procedure. The second was incorrect reduction of tibia plateau fracture. The second procedure was realized a week later for reduction and correction. A second procedure was performed in 7 patients, 5 of them for secondary complications of ICEF and two for bone coverage with a soleus flap and a pedicle sural flap. Table 3 reports all the complications.

Table 2: Differents types of procedures

\begin{tabular}{|c|c|c|c|}
\hline & & $\mathbf{N}$ & $\%$ \\
\hline \multirow{4}{*}{$\begin{array}{l}\text { Fractures } \\
\text { fixations }\end{array}$} & Tibial plateau fracture & 14 & 31,9 \\
\hline & Shaft Fracture & 13 & 25,5 \\
\hline & Pilon tibial fracture & 3 & 6,4 \\
\hline & Compound tibia plateau and shaft & 1 & 2,1 \\
\hline & Ankle fusion & 5 & 10,6 \\
\hline $\mathrm{Co}$ & tion of neglected clubfoot & 4 & 8,5 \\
\hline Fixation af & $\begin{array}{l}\text { econstruction in long bone defect } \\
\text { with bone graft }\end{array}$ & 2 & 4,2 \\
\hline Prote & of skin graft around the leg & 2 & 4,2 \\
\hline & tomy and bone fixation & 1 & 2,1 \\
\hline Stabilisat & $\begin{array}{l}\text { of ankle after reduction of ankle } \\
\text { dislocation }\end{array}$ & 1 & 2,1 \\
\hline Temporar & mur bone fixation after resection & 1 & 2,1 \\
\hline & Total & 47 & 1000 \\
\hline
\end{tabular}

Late complications after removal of the fixative were found in $13(27.7 \%)$ patients. They included: complex regional pain syndrom $(2 ; 4.2 \%)$, knee stiffness $(8 ; 17 \%)$, one ankle stiffness $(1 ; 2.1 \%)$, ankle fusion non-union $(1 ; 2.1 \%)$ and osteomyelitis $(1 ; 2.1 \%)$. Five $(10,5 \%)$ majors complications requiring a second procedure were noticed (table 3 ).

The mean delay of frame removal was $98.7+/-40$ [13 - 210] days or 24.5 weeks. Positive outcomes were achieved in 44 $(95.6 \% ; n=46)$ patients. It was effective after mean delay of 85.6 +/- 35 [15 - 183] days. These outcomes included: bone consolidation, bone integrity in the area of defect, absence of deformity recurrence, fusion maintained in ankle arthrodesis). Two $(4.4 \% ; n=46)$ bad outcomes were observed. The first after fixation for open fracture of the tibia was complicated of infected non-union. The second is non-union of fusion in a 46-year-old woman after ankle arthrodesis.
Table 3: Different type of complications according to severity

\begin{tabular}{|c|c|c|}
\hline & Type de complications & $\mathbf{n}(\mathbf{\%})$ \\
\hline \multirow{4}{*}{$\begin{array}{c}\text { Minors } \\
\text { Complications }\end{array}$} & Wire tract infection & $11(23,4)$ \\
\cline { 2 - 3 } $\mathrm{n}=31(65,9 \%)$ & Pain & $6(12,8)$ \\
\cline { 2 - 3 } & Skin necrosis around the K-wire & $1(2,1)$ \\
\cline { 2 - 3 } & Flap superficial infection & $1(2,1)$ \\
\cline { 2 - 3 } & Superficial infection & $1(2,1)$ \\
\cline { 2 - 3 } & Partials toes necrosis & $1(2,1)$ \\
\cline { 2 - 3 } & Knee stiffness (flexion $\left.>15^{\circ}\right)$ & $7(15,9)$ \\
\cline { 2 - 3 } & Ankle stiffness (flexion > 15 $\left.5^{\circ}\right)$ & $1(2,1)$ \\
\cline { 2 - 3 } Majors & Complex regional pain syndrom & $2(4,2)$ \\
\hline \multirow{4}{*}{$\begin{array}{c}\text { Complications } \\
\mathrm{n}=5(10,6 \%)\end{array}$} & Common fibular nerve injury & $1((2,1)$ \\
\cline { 2 - 3 } & Lost of reduction & $1(2,1)$ \\
\cline { 2 - 3 } & Deep infection & $1(2,1)$ \\
\cline { 2 - 3 } & Osteomyelitis & $1(2,1)$ \\
\cline { 2 - 3 } & Non-union & $1(2,1)$ \\
\hline
\end{tabular}

\section{Discussion}

The objective of this retrospective study was to report the outcomes of 47 patients managed by Ilizarov circular external fixator (ICEF) in various injuries in orthopedic trauma in low incomes country. This series, although short, has the advantage of being a single operator with continuous monitoring of patients.

Data from the literature demonstrate the great effectiveness of the ICEF technique for transosseous fixation for the treatment of a wide range of pathologies in trauma and orthopedics. The positive outcomes rate in our study $(95.6 \%)$ is similar to that reported in the literature. Indeed Soldotov et al. ${ }^{[11]}$, in a review of the literature report a $95 \%$ of positive outcomes about 4,200 cases of all the pathologies treated and greater than $90 \%$ in each of the groups of pathologies. These pathologies can be classified into 4 groups: closed reduction and fixation of bone in fractures and nonunions; operative and bloodless limb lengthening; correction of deformities and management of lone bone defects without bone graft; compression arthrodesis of joints. The effectiveness of ICEF is similar to other fixation methods ${ }^{[11]}$. On the other hand, there is a significant difference in favor of ICEF when taking account the economic factor. In our study the ICEF permit to have a good outcome with low cost the complex fractures and deformity because only the pins were payed by the patient.

These procedures were really more expensive in out setting when the fixation was achieved done by others implant. The rate of failure outcome in the use of ICEF can be estimated at 4 to $5 \%$ according to the publications ${ }^{[11]}$. In our study, the first bad outcome was related to the economic factor because the patient could no longer pay for the various procedures 
required. The second case of failure was due to a lack of follow-up, the patient having missed the various checks.

In our series, all the procedures focused only on the pelvic limb. They were dominated by osteosynthesis of fractures of the tibia with complex lines $(65.9 \%)$ among which tibia plateau fractures were the most important. Indeed the leg segment remains the most important seat in the literature for osteosyntheses by the ICEF because of the predominance of tibia fractures but also the ease of use on the leg segment where it was initially designed for lengthening of member ${ }^{[1}$, ${ }^{2]}$. Thus the ICEF has several advantages with excellent results for type IV to VI fractures of Schatzker, comminuted or open diaphyseal fractures and complex fractures of the tibial pilon compared to other types of osteosynthesis [12], [13], [14].

Ankle fusion was the second most performed procedure $(10.6 \%)$ followed by equine varus foot corrections $(8.5 \%)$ in our series. This last indication was less practiced in our setting due to insufficiency of skills. The ICEF allows the correction of several deformities of the limbs, in particular Charcot arthropathies, vicious ankle calluses, angular deformities, rigid equinus varus feet in adults and children [15], ${ }^{[16]}$. It offers the advantage of a minimally invasive approach, axial compression, an elongation of limb length inequality, a progressive correction in the equine varus feet or over time, early loading promoting consolidation ${ }^{[16]}$.

A particular indication reported in our series was the protection of circular thin skin graft by ICEF (Fig. 2C, D). The ICEF had allowed an elevation of the leg avoiding contact on the skin graft areas. This facilitated wound healing, dressing changes, and joints motion. This indication has not been reported in the literature to our knowledge. Two osteosyntheses were made by the ICEF after reconstructions of loss of diaphyseal bone substance in the tibia. One was a composite flap of free vascularized fibula (Fig. 2A). In the literature, reconstruction by bone transfer with Ilizarov method is the most widely used technique ${ }^{[17],[18]}$. In our case, the fixative offered the advantage of being minimally invasive, of progressive dynamization, and did not interfere with the graft.

The average duration of approximately was similar to that of open or closed fracture osteosynthesis procedures. This duration was longest in ankle fusions and osteosynthesis of tibial plateau fractures for several reasons. The built of the Ilizarov frame was done intraoperatively and not previously prepared, the other operators were poorly trained in the technique and had little knowledge of the set. However, this duration, had no impact on the risk of infection or bleeding because it is usually bloodless surgery.

Complications are very common [19], [20]. Two to four complications can be observed in the same patient ${ }^{[20]}$. Pin infections are the most frequent ranging from 17.03 to $100 \%$ of the cases treated ${ }^{[11],[20]}$. In our study this pin track infection healed with local dressing. The iatrogenic lesion of the common fibular nerve was observed, due to the passage of the pin over the nerve is rare. It is recommended to place a pin taking the head of the fibula remaining $1 \mathrm{~cm}$ above the passage of the nerve which ties the neck of the fibula ${ }^{[21]}$. In our series, the two cases of osteitis and deep bone infection were linked first to the open fracture and then due to the patient's lack of resources, who have to pay for the multiple procedures on its own. These deep infectious complications are common in open fractures regardless of the type of fixation [12], [22]. Complications in Ilizarov technique related most of cases do not often affect the outcome however it is not acceptable to obtain an excellent radiological result and a poor functional result because of insufficient postoperative and follow-up care ${ }^{[23,24]}$

\section{Conclusion}

Ilizarov technique gives solution in difficult and problematic tibial fractures, leg and foot deformities. The outcomes of these various orthopedic and trauma pathologies in our context is good. The management of these complex cases had been possible with a low cost for the implant. It had been helpful to preserve and improve the prognosis of limb for patients who most often do not have insurance policy. In order to broaden the indications and increase surgeons skills, it is necessary to initiate training in our context or in foreign country in this technique.

\section{References}

1. Gubin AV. Ilizarov's phhilosophy as a base of new subspeciality in traumatology and orthopaedics. Genji Orthopedii. 2019; 25(4):449-51.

2. Gubin AV, Borzunov DY, Malkova TA. The Ilizarov paradigm: thirty years with the Ilizarov method, current concerns and future research. Int Orthop. 2013; 37(8):1533-39

3. Abdelsatar T, Elsawy M, Zayda A, Samy A. Management of segmental tibial fractures by an Ilizarov external fixator. Menoufia Med J. 2016; 29:680-4.

4. El-Gafary K, El-Adly W, Farouk O, Khaled M, Abdelaziz MM. Management of high-energy tibial plateau fractures by Ilizarov external fixator. Eur Orthop Traumatol. 2014; 5(1):9-14.

5. Hosny G, Fadel M. Ilizarov external fixator for open fractures of the tibia shaft. International Orthopaedics. 2003; 27:303-306.

6. Schatzker J, McBroom R, Bruce D. The tibial plateau fractures. The Toronto experience 1968-1975. Clin Orthop Relat Res, 1979, 94-104.

7. Meinberg EG, Agel J, Roberts CS, Karam MD, Kellam JF. Fracture and dislocation classification compendium. J Orthop Trauma. 2018; 32(Suppl 1):S1-S170.

8. Gustilo RB, Anderson JT. Prevention of infection in the treatment of one thousand and twenty-five open fractures of long bones: retrospective and prospective analyses. J Bone Joint Surg Am. 1976; 58:453-458.

9. Oestern HJ, Tscherne H. Pathophysiology and classification of soft issue injuries associated with fractures. In: Tscherne $\mathrm{H}$, editor. Fractures with soft tissues injuries. New York: Springer-Verlag, 1984, 1-9.

10. Velazquez RJ, Bell DF, Armstrong PF, Babyn P, Tibshirani R. Complications of use of the Ilizarov technique in the correction of limb deformities in children. J Bone Joint Surg Am. 1993; 75(8):1148-56.

11. Soldatov YP, Stogov MV, Ovnchinnikov EN, Gubin AV, Gorodnova NV. Evaluation of clinical efficacy and safety of the Ilizarov apparatus for external fixation (literature review). Genji Orthopedii. 2019, 25(4):588-99.

12. Wani N, Baba A, Kangoo K, Mir M. Role of early Ilizarov ring fixator in the definitive management of type II, IIIA and IIIB open tibial shaft fractures. Int Orthop. 2011; 35(6):915-23.

13. Abdelsatar T, Elsawy M, Zayda A, Samy A. Management of segmental tibial fractures by an Ilizarov external fixator. Menoufia Med J. 2016; 29:680-4

14. Metcalfe D, Hickson CJ, Mckee L, Griffin Xl. External versus internal fixation for bicondylar tibial plateau 
fractures: systematic review and meta-analysis. J Orthop Traumatol. 2015; 16(4):275-85.

15. Makhdoom A, Qureshi Pal, Jokhio Mf, Siddiqui Ka. Resistant clubfoot deformities managed by Ilizarov distraction histogenesis. Indian J Orthop. 2012; 46(3):326-32.

16. Rabinovich RV. Haleem Am, Rozbruch Sr. Complex ankle arthrodesis: Review of the literature. World J Orthop. 2015; 6(8):602-13

17. Fletcher C. Use of Bone Transport in the Management of Large Diaphyseal Tibial Defects. Orthop Rheumatol Open Access J. 2017; 9(3):1-4.

18. Mccoy TH, Kim HJ, Cross MB, Fragomen AT, Healey $\mathrm{JH}$, Athanasian EA et al. Bone tumor reconstruction with the Ilizarov method: Ilizarov Reconstruction of Bone Tumors. J Surg Oncol. 15 mars 2013; 107(4):343-52.

19. Bakhshi AS, Kumar S, Singh J, Sood M, Jain AK. Complications of Ilizarov ring fixator and their management. IJOS. 2019; 5(4):839-44.

20. Bakhshi Das, Kumar DS, Singh DJ, Sood DM, Jain Dak. Complications of Ilizarov ring fixator and their management. Int J Orthop Sci. 2019; 5(4):839-44.

21. Ferreira N, Mare PH, Marais LC. Circular external fixator application for midshaft tibial fractures: surgical technique. Orthopaedic journal. 2012; 11(4):39-42

22. Kayode MO, Adewole OA, Shoga MO, Giwa SO. Experience with managing complicated fractures using Ilizarov principle in Lagos, Nigeria. J West Afr Coll Surg. 2017; 7(3):24-42.

23. Dahl MT, Gullì B, Berg T. Complications of limb lengthening. A learning curves. Clin Orthop. 1994; 301:10-8.

24. Sella EJ. Prevention and Management of Complications of the Ilizarov Treatment Method. Foot Ankle Spec. 2008; 1(2):105-7. 